\title{
Single nucleotide polymorphisms in genes MACC1, RAD18, MMP7 and SDF-1a as prognostic factors in resectable colorectal cancer
}

\author{
Matej Horvat ${ }^{1}$, Uros Potocnik ${ }^{2,3}$, Katja Repnik²,3, Rajko Kavalar, Vesna Zadnik ${ }^{5}$, \\ Stojan Potrc ${ }^{6}$, Borut Stabuc ${ }^{7}$ \\ ${ }^{1}$ Department of Oncology, University Medical Centre Maribor, Slovenia \\ ${ }^{2}$ Centre for Human Molecular Genetics and Pharmacogenomics, Faculty of Medicine, University of Maribor, Slovenia \\ ${ }^{3}$ Laboratory for Biochemistry, Molecular Biology and Genomics, Faculty for Chemistry and Chemical Engineering, University \\ of Maribor, Slovenia \\ ${ }^{4}$ Department of Pathology, University Medical Centre Maribor, Slovenia \\ ${ }^{5}$ Epidemiology and Cancer Registry, Institute of Oncology Ljubljana, Slovenia \\ ${ }^{6}$ Department of General and Abdominal Surgery, University Medical Centre Maribor, Slovenia \\ 7 Department of Gastroenterology, University Medical Centre Ljubljana, Slovenia
}

Radiol Oncol 2017; 51(2): 151-159.

Received 5 February 2016

Accepted 27 May 2016

Correspondence to: Prof. Borut Štabuc, Ph.D., M.D., Department of Gastroenterology, University Medical Centre Ljubljana, Slovenia. E-mail: borut.stabuc@kclj.si

Disclosure: No potential conflicts of interest were disclosed.

Background. Colorectal cancer (CRC) represents one of the most common malignancies worldwide. Research has indicated that functional gene changes such as single nucleotide polymorphism (SNP) influence carcinogenesis and metastasis and might have an influence on disease relapse. The aim of our study was to evaluate the role of SNPs in selected genes as prognostic markers in resectable CRC.

Patients and methods. In total, 163 consecutive patients treated surgically for CRC of stages I, II and III at the University Medical Centre in Maribor in 2007 and 2008 were investigated. DNA was isolated from formalin-fixed paraffin-embedded CRC tissue from the Department of Pathology and SNPs in genes SDF-1a, MMP7, RAD 18 and MACC1 were genotyped using polymerase chain reaction followed by high resolution melting curve analysis or restriction fragment length polymorphism.

Results. We found worse disease-free survival (DFS) for patients with TT genotype of SNP rs 1990172 in gene MACCl (p $=0.029)$. Next, we found worse DFS for patients with GG genotype for SNP rs373572 in gene RAD $18(p=0.020)$. Higher frequency of genotype GG of MMP7 SNP rs 11568818 was found in patients with T3/T4 stage ( $p=0.014)$, N1/N2 stage $(p=0.041)$ and with lymphovascular invasion $(p=0.018)$. For MACCl $\mathrm{rs} 1990172$ SNP we found higher frequency of genotype $\pi$ in patients with $T 3 / T 4$ staging $(p=0.024)$. Higher frequency of genotype GG of RAD 18 rs 373572 was also found in patients with $\mathrm{T} 1 / \mathrm{T} 2$ stage with disease relapse $(\mathrm{p}=0.041)$.

Conclusions. Our results indicate the role of SNPs as prognostic factors in resectable CRC.

Key words: single nucleotide polymorphism; colorectal cancer; MACC1; RADI8; MMP7; SDF-1a

\section{Introduction}

Colorectal cancer (CRC) represents the third most common malignancy worldwide in men and sec- ond most common malignancy in women, accounting for approximately $10 \%$ of all tumour types worldwide and $8 \%$ of cancer related mortality. ${ }^{1}$ In Slovenia according to Cancer registry of 
Slovenia yearly reports, CRC is the second most common cancer in men and women. The incidence was steadily increasing in the last decades. From 2001 to 2011 it has risen by 35\%, from 1110 in 2001 to 1709 in 2010 when it reached its peak. The incidence is now declining with 1530 in 2012. There is also a relative proximal shift of tumour location with the incidence of colon cancer increasing faster than the incidence of rectal cancer. ${ }^{2-5}$

The survival of CRC is improving as a consequence of screening programs, new chemotherapy regimens and targeted treatments as well as improved surgical treatment of metastatic disease. According to Surveillance, Epidemiology, and End Results (SEER) register and a worldwide CONCORD-2 study, the 5-year CRC survival in developed countries is more than $60 \%$. 6,7

$\mathrm{CRC}$ is a heterogeneous disease and its cancerogenesis a multistep process. CRC develops in 75\% sporadically because of mutations acquired during a person's lifetime and in $25 \%$ as a combination of hereditary syndromes, a higher risk because of CRC familial burden without criteria for a hereditary syndrome or as a consequence of inflammatory bowel syndrome. ${ }^{8}$ It evolves through distinct genetic pathways: chromosomal instability, microsatellite instability (MSI-H) and the CpG island methylator phenotype (CIMP). Next to "classical adenoma-carcinoma « sequence proposed by Fearon and Voglestein there is also a newly recognized »serrated neoplasia pathway«, where CRC evolves through different precancerous lesions, as for instance serrated adenoma. ${ }^{9}$ The carcinogenesis might also differ in regard to CRC arising either in right or left hemicolon. ${ }^{10}$

The current treatment for resectable CRC of stage I, II and III is surgical resection. For patients of stage I, surgical resection is the only recommended treatment without adjuvant chemotherapy. For patients of stage III adjuvant chemotherapy is recommended in all patients. In contrast for patients of stage II adjuvant chemotherapy is not recommended for unselected patients, but for those with clinical or pathological risk factors. ${ }^{11-13}$

Potential clinical and pathological risk factors for recurrence of stage II CRC have been investigated and incorporated in different guidelines, but a definite consensus has not yet been reached. According to European and American guidelines (The European Society for Medical Oncology (ESMO), The American Society of Clinical Oncology (ASCO) and The National Comprehensive Cancer Network (NCCN)), negative prognostic risk factors according to all three sets of guidelines are: T4 tumours, bowel perforation, extension of surgical lymphadenectomy, inadequate pathological sampling of lymph nodes and poor tumour differentiation grade. Further negative prognostic markers included in one or two sets of guidelines are: bowel obstruction, lymphovascular invasion and/or perineural invasion and indeterminate or positive margins. Consensus on them has not been reached yet. There is no clear message regarding adjuvant chemotherapy patient selection in stage II CRC. ${ }^{11-13}$

Although stage I and early stage II CRC are prognostically very favourable, with a small burden of disease, a proportion of these tumours have certain characteristics, making them clinically more malignant and therefore predisposing them to disease recurrence or metachronous colon cancer. ${ }^{9}$ Up to $30 \%$ of patients with stage I and up to $50 \%$ of patients with stage II of CRC are going to relapse. ${ }^{14,15}$ Considering these facts it is clear that classical TNM staging system has its limitations, so it is necessary to determine molecular or immunological prognostic and predictive markers to implement in routine clinical practice. ${ }^{16,17}$

Single nucleotide polymorphisms (SNPs) are molecular factors that might be useful as prognostic markers in CRC. Preliminary genome wide association (GWA) study in non-caucasian population has indicated a role of SNPs in resectable CRC. ${ }^{18}$ We hypothesized that SNPs participating in genetic risk for $\mathrm{CRC}$ and metastasis might prove as a prognostic factor in resectable CRC. In our study, we have selected SNPs with higher frequency in patients with either local lymph node involvement or systemic dissemination in genes participating in CRC carcinogenesis and disease dissemination: $S D F-1 \alpha$ (stromal derived factor 1 alpha) located on chromosome 10, MMP7 located on chromosome 11, RAD18 located on chromosome 3, and MACC1 (metastasis associated in colorectal cancer 1) located on chromosome $7 .{ }^{19-22}$ The aim of our study was to evaluate the role of SNPs in selected genes as prognostic markers in resectable CRC.

\section{Patients and methods}

We have conducted a study, regarding the role of selected SNPs in resectable CRC. In total, 163 consecutive patients treated surgically at University Medical Centre in Maribor in years 2007 and 2008 have been investigated. The inclusion criterion was colorectal adenocarcinoma of stages I, II or III. The exclusion criteria were: history of inflammatory bowel disease, preoperative chemoradiotherapy/ 
radiotherapy, perioperative mortality within 30 days and confirmed familial CRC (FAP, HNPCC or other familial syndromes). Mean age of the patients at diagnosis was 67 years +/- 11.4 years (range 26-88 years). Clinical and pathohistological characteristics examined were: age, gender, TNM stage, differentiation grade, perineural invasion and lymphovascular invasion. Time to progression was defined as time from diagnosis to progression. Patients were followed-up on average for 69 months. Data regarding their vital status was acquired from Cancer registry of Slovenia. Clinical and pathohistological characteristics of patients and tumours are summarized in Table 1.

\section{DNA isolation and SNP genotyping}

DNA was extracted from the formalin-fixed paraffin-embedded (FFPE) CRC tissues of 163 patients from the Department of Pathology, University Medical Centre in Maribor. FFPE tissues were prepared as follow: at macroscopic examination of resected specimen, the pathologist sampled representative tissue samples $(2 \times 2 \times 0.4 \mathrm{~cm})$ from tumour, bowel wall outside the tumour and all lymph nodes from the resected pericolic or mesorectal fat. For determination of resection margin status, the representative tissue samples were taken also from the proximal and distal intestinal resection margin, from circumferential resection margin and dyed with the indian-ink. All representative tissue samples and all obtained lymph nodes were put into labeled histo-casettes and standardly processed in automated histoprocessors (dehydrated and paraffined). Paraffined tissue samples were embedded in paraffin blocks. For the extraction of DNA, $12 \mu \mathrm{m}$ thick tissue slices were cut with microtome from tumour tissue blocks.

DNA was isolated from FFPE tissues using BiOstic FFPE Tissue DNA Isolation Kit ${ }^{\circledR}(\mathrm{MO}$ BIO Laboratories, Inc.) according to manufacturer recommendations. SNPs of genes SDF-1 $\alpha$ (rs1801157), MMP7 (rs11568818), RAD18 (rs373572) in MACC1 (rs1990172) were genotyped using polymerase chain reaction $(\mathrm{PCR})$ followed by high resolution melting (HRM) or restriction fragment length polymorphism (RFLP) techniques. Forward and reverse primer sequences, size of product after PCR, primer concentrations, annealing temperatures and genotyping method are shown in Table 2 . HRM genotyping was performed using real time PCR LC480 instrument (Roche, Germany). PCRHRM was carried out using LC480 HRM Master Mix (Roche, Germany). Conditions were as follow:
TABLE 1. Clinical and pathohistological characteristics of patients included in study

\begin{tabular}{|c|c|}
\hline Clinical and histopathological characteristics & CRC patients $(N=163)$ \\
\hline $\begin{array}{l}\text { Sex } \\
\quad \text { Male/female, } N(\%)\end{array}$ & $92 / 71(56.4 / 43.6)$ \\
\hline $\begin{array}{l}\text { Age at diagnosis } \\
\text { Mean }+/-S D\end{array}$ & $67.28+/-11.44$ \\
\hline $\begin{array}{l}\text { Stage of disease, } N(\%) \\
\text { II } \\
\text { III }\end{array}$ & $\begin{array}{l}29(17.8) \\
81(49.7) \\
53(32.5)\end{array}$ \\
\hline $\begin{array}{l}\text { TNM staging } \\
\text { Tumour, } N(\%) \\
\text { T1 } \\
\text { T2 } \\
\text { T3 } \\
\text { T4 } \\
\text { Lymph nodes, N (\%) } \\
\text { NO } \\
\text { N1 } \\
\text { N2 }\end{array}$ & $\begin{array}{l}8(4.9) \\
24(14.7) \\
120(73.6) \\
11(6.7) \\
110(67.5) \\
38(23.3) \\
15(9.2)\end{array}$ \\
\hline $\begin{array}{l}\text { Vital status (5.10.2015), N (\%) } \\
\text { dead } \\
\text { alive }\end{array}$ & $\begin{array}{l}65 \text { (39.9) ( } 42 \text { due to CRC } \\
\text { progression, } 23 \text { other cause) } \\
98 \text { (60.1) }\end{array}$ \\
\hline $\begin{array}{l}\text { Disease progression, } N(\%) \\
\quad \text { yes } \\
\text { no }\end{array}$ & $\begin{array}{l}46 \text { (28.2) (42 dead, } 4 \text { alive) } \\
117(71.8)\end{array}$ \\
\hline $\begin{array}{l}\text { Disease progression according to stage, } N(\%) \\
\text { stage I } \\
\text { stage II } \\
\text { stage III }\end{array}$ & $\begin{array}{l}5(17.2) \\
18(22.2) \\
23(43.4)\end{array}$ \\
\hline $\begin{array}{l}\text { Clinical characteristics, } N(\%) \\
\text { more than } 12 \text { lymph nodes resected } \\
\text { adjuvant therapy }\end{array}$ & $\begin{array}{l}70(42.9) \\
41(25.2)\end{array}$ \\
\hline $\begin{array}{l}\text { Differentiation grade, } N(\%) \\
\quad \text { II } \\
\text { III } \\
\text { no data }\end{array}$ & $\begin{array}{l}66(40.5) \\
74(45.4) \\
21(12.9) \\
2(1.2)\end{array}$ \\
\hline $\begin{array}{l}\text { Perineural invasion, } N(\%) \\
\text { yes } \\
\text { no }\end{array}$ & $\begin{array}{l}13(8.0) \\
150(92.0)\end{array}$ \\
\hline $\begin{array}{l}\text { Lymphovascular invasion, } N(\%) \\
\text { yes } \\
\text { no }\end{array}$ & $\begin{array}{l}27(16.6) \\
136(83.4)\end{array}$ \\
\hline
\end{tabular}

$N=$ number of patients

initial denaturation at $95^{\circ} \mathrm{C}$ for $10 \mathrm{~min}$, followed by 45 cycles of $95^{\circ} \mathrm{C}$ for $10 \mathrm{~s}, 57$ or $60^{\circ} \mathrm{C}$ (primer pair dependent) for $15 \mathrm{~s}$ and $72^{\circ} \mathrm{C}$ for $10 \mathrm{~s}$, followed by HRM step of $95^{\circ} \mathrm{C}$ for $1 \mathrm{~min}, 40^{\circ} \mathrm{C}$ for 1 min and $60-90^{\circ} \mathrm{C}$ at $0.02^{\circ} \mathrm{C} / \mathrm{s}$. PCR-RFLP conditions were as follow: initial denaturation at $95^{\circ} \mathrm{C}$ for $5 \mathrm{~min}$, followed by 35 cycles of $95^{\circ} \mathrm{C}$ for $30 \mathrm{~s}$, 60 or $63^{\circ} \mathrm{C}$ (primer pair dependent) for $30 \mathrm{~s}$ and $72^{\circ} \mathrm{C}$ for $30 \mathrm{~s}$. After PCR, products were incubated with restriction enzymes shown in Table 2 at $37^{\circ} \mathrm{C}$ overnight. Digested products were resolved in $2 \%$ agarose gel.

Our study was approved by the National Ethics committee of Slovenia (clinical trial registration number: 65/02/13) and is listed at University 
TABLE 2. Primer sequences used in PCR reaction, expected sizes of products, annealing temperatures, primer concentrations and genotyping method of selected SNPs; restriction enzymes and sizes of fragments after restriction for genotyping of SNPs rs1801157 (CXCL12) and rs1990172 (MACC1)

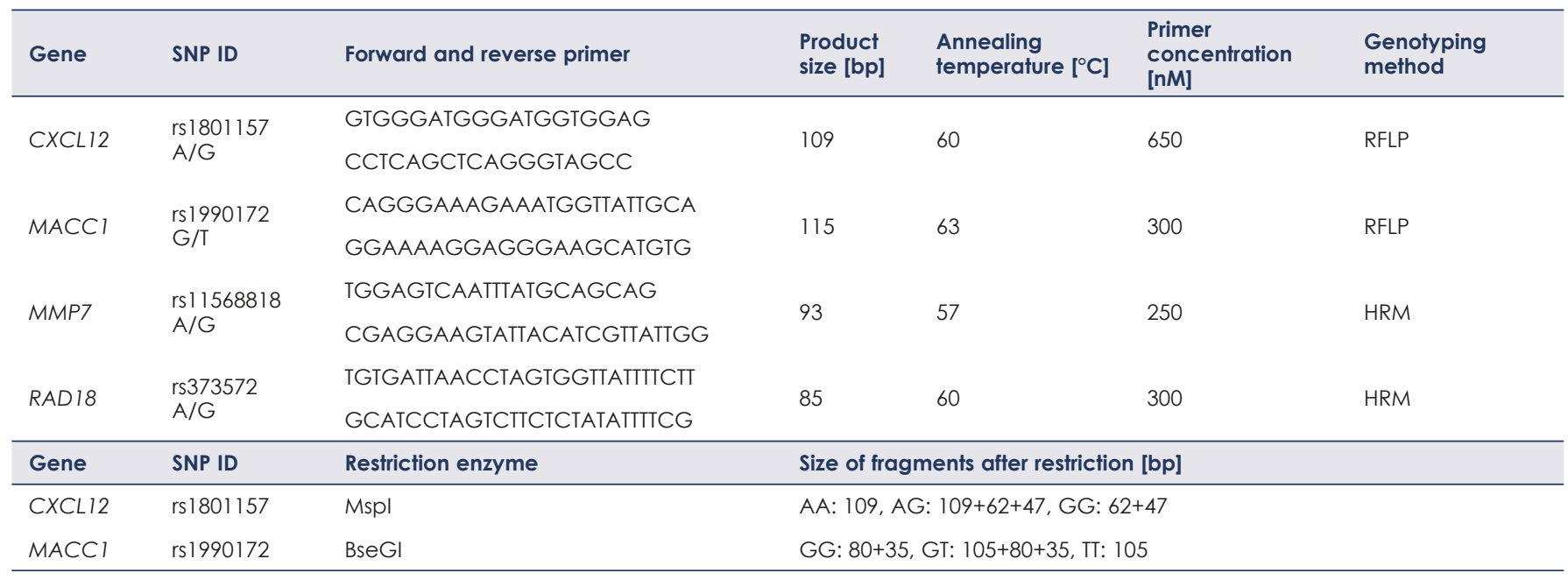

Medical Centre Maribor as research project: IRP2014/01-21.

\section{Statistical analysis}

The clinical endpoint of our trial was evaluating the role of selected SNPs as prognostic factors by determining disease-free survival from the date of the surgery. Kaplan-Meier survival curves were constructed and compared using the log-rank test. Multivariate analysis was carried out using a Cox proportional hazard model. Group distribution for each clinicopathological characteristic was compared using two-tailed Fischer exact test. Data are expressed as the mean $+/$ - standard deviation. Statistical significance was defined as $p<0.05$. All analyses were performed using SPSS.

\section{Results}

Over an average follow-up period of 69 months, 65 deaths were recorded $(39.9 \%)$. Out of those 65 patients, 42 died because of disease progression and 23 patients died of another cause.

Selected SNPs were genotyped in 163 CRC patients with well-defined clinical and histopathological characteristics. Genotype and allele frequencies were calculated for all patients and are shown in Table 3. When comparing selected SNPs with clinical and pathohistological characteristics of patients, higher frequency of genotype GG of MMP7 rs11568818 SNP was found in patients with T3/T4 staging $(29.6 \%)$ compared to patients with $\mathrm{T} 1 / \mathrm{T} 2$ staging $(7.1 \%, \mathrm{p}=0.014)$, in patients with $\mathrm{N} 1 / \mathrm{N} 2$ staging $(36.2 \%)$ compared to N0 staging $(19.8 \%$, $\mathrm{p}=0.041)$ and in patients with lymphovascular invasion $(45.8 \%)$ compared to patients without lymphovascular invasion $(21.0 \%, \mathrm{p}=0.018)$. For MACC1 rs1990172 SNP, we found higher frequency of genotype TT in patients with T3/T4 staging $(62.5 \%)$ compared to patients with $\mathrm{T} 1 / \mathrm{T} 2$ staging $(36.0 \%, p=0.024)$. All correlations between selected SNPs and clinical and histopathological characteristics are presented in Table 3.

We have further evaluated the correlation of genotype frequencies in patients with progression compared to patients without disease progression. We found association between tumour TNM staging and SNP rs373572 in gene RAD18. Higher frequency of genotype GG was found in patients with T1/T2 staging with disease progression $(60.0 \%)$ compared to patients with $\mathrm{T} 1 / \mathrm{T} 2$ staging without disease progression $(12.0 \%, \mathrm{p}=0.041)$. No statistically significant differences were discovered in rs1990172 in gene MACC1, rs1801157 in gene SDF$1 \alpha$ or rs11568818 in gene MMP7.

The results of survival analysis showed association with SNP rs1990172 in gene MACC1 and with SNP rs373572 in gene RAD18. We found worse disease-free survival (DFS) for patients with TT genotype of SNP rs1990172 in gene MACC1 compared to patients with GT or GG genotype $(\mathrm{p}=$ 0.029 , Figure 1). One year, 3 years and 5 years DFS were in patients with TT genotype $94.8 \%, 67.3 \%$ and $62.9 \%$, respectively compared to patients with 
TABLE 3. Associations between selected SNPs and clinico-histopathological characteristics of patients

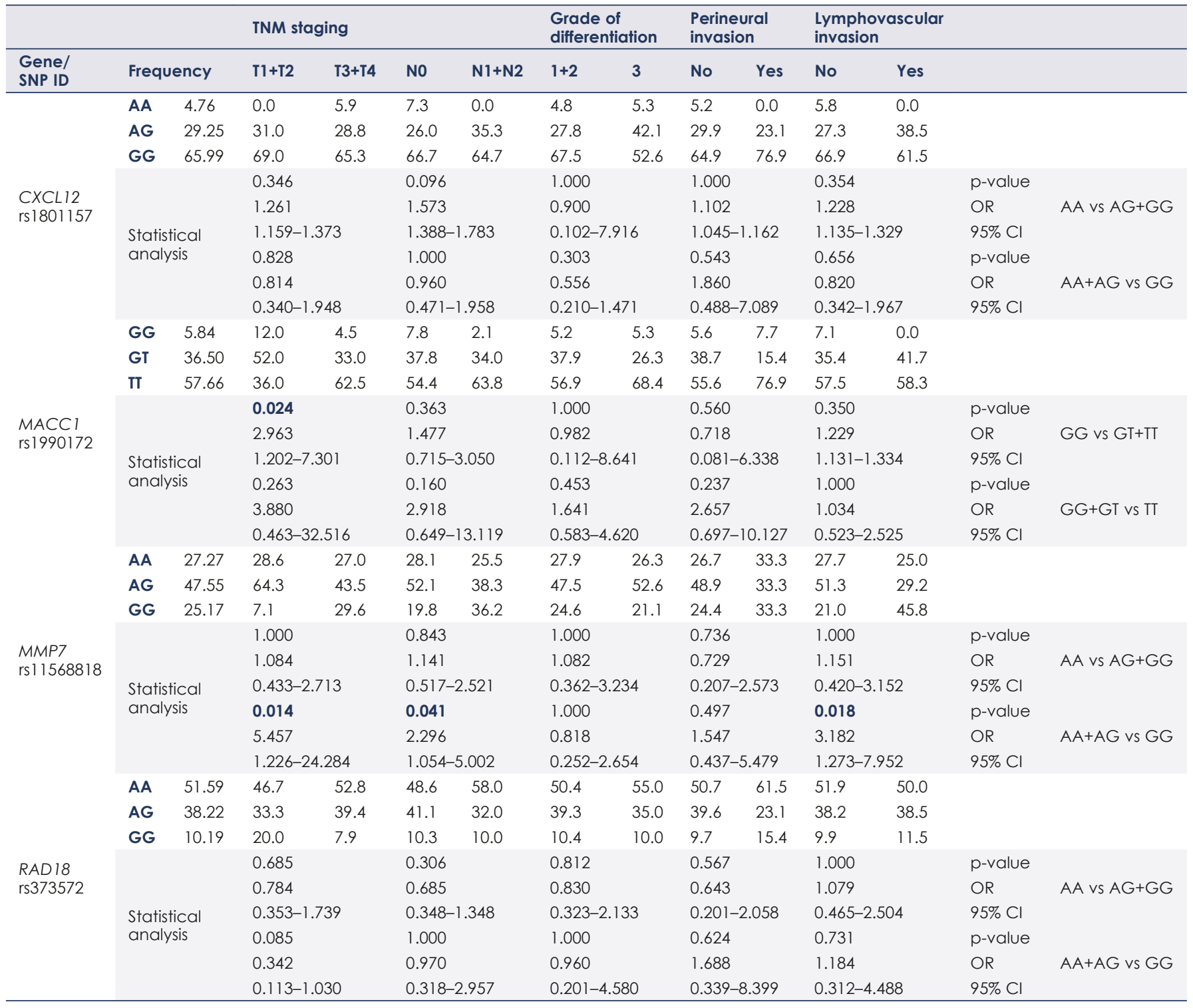

GT/GG genotype, where 1 year, 3 years and 5 years DFS were $91.1 \%, 85.7 \%$ and $78.3 \%$, respectively. Next, we found worse survival for patients with GG genotype compared to patients with AG or AA genotype for SNP rs373572 in gene RAD18 ( $\mathrm{p}=$ 0.020 , Figure 2). One year, 3 years and 5 years DFS were in patients with GG genotype $86.7 \%, 53.3 \%$ and $45.7 \%$, respectively, compared to patients with AG/AA genotype, where 1 year, 3 years and 5 years DFS were $94.9 \%, 78.9 \%$ and $74.2 \%$, respectively. The survival analysis for SNP rs11568818 in gene MMP7 and rs1801157 in gene SDF- $1 \alpha$ did not show statistically significant differences.

\section{Discussion}

Our study is the first report of the association between SNP rs373572 in RAD18 gene and SNP rs1990172 in MACC1 gene with DFS in resectable CRC. We also identified the association of SNP rs373572 in RAD18 gene in patients with stage I CRC and disease relapse.

Association between SNP rs373572 in RAD18 gene and DFS has been found, where 5-year DFS was significantly shorter for patients with GG genotype compared to patients with AA or AG genotype. Multivariate analysis showed that GG 


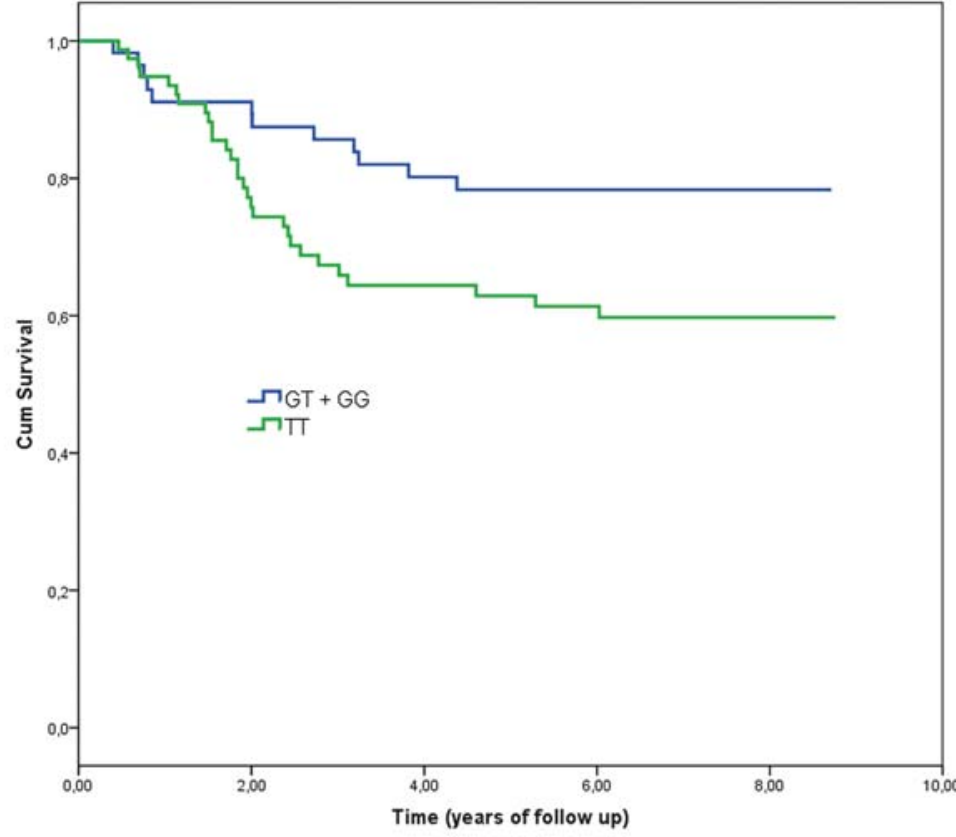

FIGURE 1. Survival analysis curves for different genotype groups of CRC patients according to SNP rs 1990172 in gene MACCl.

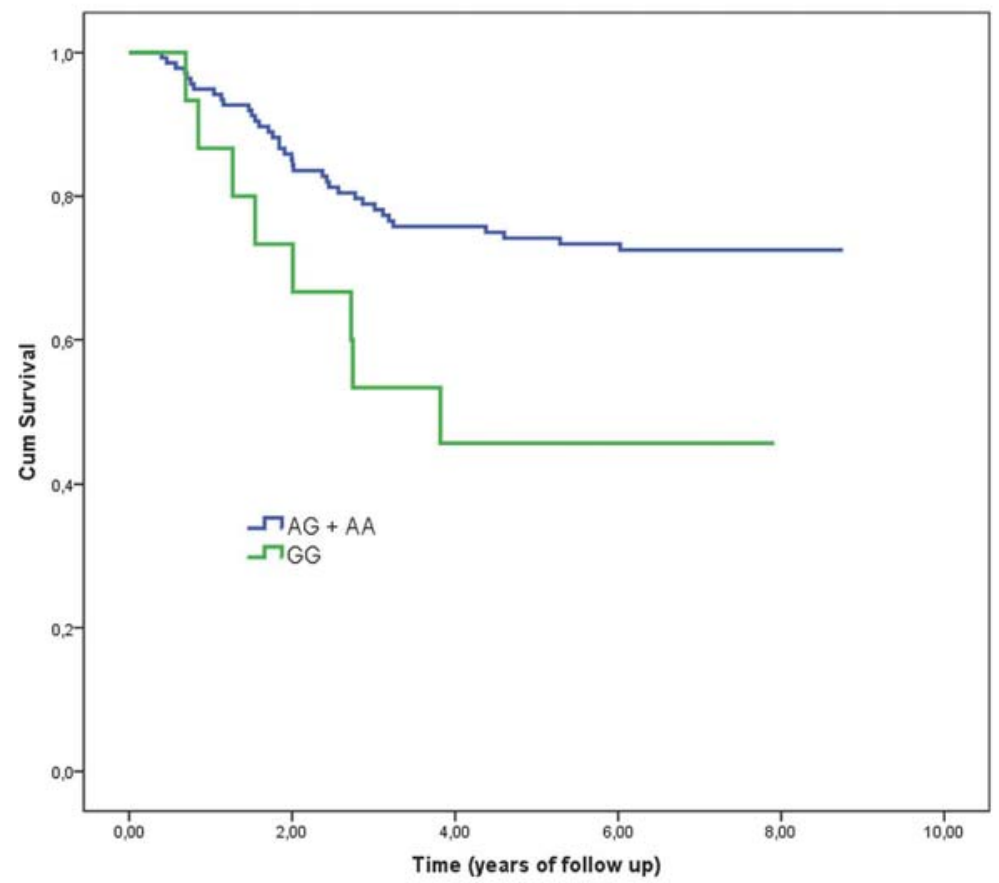

FIGURE 2. Survival analysis curves for different genotype groups of CRC patients according to SNP rs373572 in gene RAD 18.

genotype could be independent negative prognostic factor, however association was at a borderline of statistical significance. In patients with stage I CRC, the GG genotype was more frequent in patients who relapsed, making it a potential negative prognostic factor for early stage CRC. RAD18 gene combines two distinct pathways maintaining genome stability. ${ }^{23}$ So far, association between SNP rs373572 and increased risk for CRC has been confirmed and significant association between SNP and clinicopathological features, specifically in differentiated grade and lymph node metastasis has been found in Japanese population. ${ }^{21}$ Association between rs373572 and CRC (colon and rectum cancer) has been also found in Han Chinese and it was shown that SNP is significantly related with increased risk of metastasis in CRC. ${ }^{24}$ Interestingly, this study showed in contrary better prognosis for patients with GG genotype. Further, statistically significant association has been found between MACC1 intron rs1990172 SNP genotype GT or TT and higher T stage of TNM. Patients with GT or GG genotype also had higher 5-years DFS compared to patients with TT genotype. Multivariate analysis showed that TT genotype was an independent negative prognostic factor. This may partially explain the poorer prognosis of patients with TT genotype. MACC1 is a regulator of the HGF/ Met signaling pathway which plays a key role in regulating many biological processes including cellular proliferation, cell metastasis, cell invasiveness, angiogenesis, epithelial mesenchymal transition, inducing increased invasiveness, tumorigenesis and also chemoresistance. ${ }^{25}$ The expression levels of MACC1 in colon cancer without distant metastases was significantly higher in primary tumours that later developed distant metastases, compared to those that did not metastasize within a 10-year-follow-up period. ${ }^{26}$ Several SNPs have been discovered in human MACC1 gene and Lang et al. ${ }^{27}$ conducted a trial researching six SNPs in MACC1 gene and they report a positive association of the MACC1 tagging SNP rs1990172 with reduced overall survival in patients with CRC. The study showed, in contrary to our results, better prognosis for patients with TT genotype. There are some differences in the design and clinical endpoint comparing both studies. Lang et al. also included patients with metastatic disease making the patient population more heterogenous. Their clinical endpoint was also overall survival (OS) not DFS. The authors concluded that rs1990172 was significantly associated with an increased risk for any death, not just CRC related. As we see in our study, out of 65 patients who died in course of follow up, 42 died of CRC recurrence and in 23 patients'cause of death was different. Considering this, DFS is more reliable to evaluate the role of a prognostic factor in adjuvant setting than OS. 
Association between MACC1 rs1990172 SNP and other cancers has been found. For example, in patients with HER2-positive breast cancer, increased risk for progression or death for carriers of the $G$ allele of SNP rs1990172 has been found. ${ }^{28}$

In our study we also found association between genotype GG of MMP7 gene promoter SNP rs11568818 and higher tumour (T) TNM stage, with regional lymph node dissemination and lymphovascular invasion. Our results suggest, that GG genotype of MMP7 rs11568818 SNP is negative prognostic biomarker for CRC. Consistent with our results, genotype GG of SNP rs11568818 in MMP7 has been recently associated with patients with CRC and aggressive course of the disease and with higher regional lymph node involvement. ${ }^{29}$ In this study relationship between GG genotype of $M M P 7$ rs11568818 SNP and advanced tumour infiltration has also been reported. Higher prevalence of MMP7 rs11568818 GG genotype was also found among bladder cancer patients compared to controls, however, SNP was not associated with the tumour grade or stage. ${ }^{30}$ In meta-analysis of $M M P 2$, $M M P 7$ and MMP9 promoter polymorphisms, AG and GG genotype carriers of MMP7 rs11568818 SNP had an increased gastric cancer risk, suggesting it may play allele-specific role in cancer development. ${ }^{31}$ In breast cancer, statistically significant association with disease-free survival (DFS) was found for MMP7 rs11568818 SNP, where patients homozygous for $\mathrm{G}$ allele had significantly worse prognosis. ${ }^{32}$ In our study, statistically significant association with 5-year DFS for MMP7 rs11568818 SNP has not been found. Altogether, MMP7 seems very promising candidate for predicting tumour progression and metastasis also in CRC patients, particularly since it was also found, that the overexpression of $M M P 7$ has considerable metastatic potential and correlates with unfavourable clinicopathological characteristics. ${ }^{33}$

We also investigated SNP rs1801157 in CXCL12 $(S D F-1 \alpha)$ gene. The CXCL12/CXCR4 axis promotes metastasis in numerous cancers. CXCL12 is being produced and released from tissues as liver or lung and trigger the migration of tumour cells expressing with CXCR4 receptor thereby promoting invasion, proliferation and survival under suboptimal condition. ${ }^{34}$ SNPs in CXCL12 gene have also been studied as a factor of increased likelihood developing cancer and increased likelihood of dissemination. ${ }^{35,36}$ In a clinical trial conducted by Chang et al. ${ }^{37}$, GA/AA genotype of SNP rs1801157 was significantly higher in patients with lymph node metastasis among T3 tumours. In addition, an in- vestigation of the relationship between CXCL12 genotypes and different clinico-pathological prognostic factors revealed a positive association between the GA/AA genotype and lympho-vascular invasion. Both of these results indicate a predisposition to worse prognosis. In our study we haven't confirmed statistically significant association for SNP rs1801157 CXCL12 gene in 5-year DFS nor correlation between genotype distribution and clinicopathological characteristics. However, the distribution of genotypes was in our study similar compared to other studies. ${ }^{37}$ They however discovered higher AA genotype frequency in patients with T3 CRC in regional lymph node dissemination and lymphovascular invasion. Survival analysis showed worse DFS for the AA genotype in patients with lymph metastases. ${ }^{37}$

Stage III CRC patients are those who benefit from adjuvant chemotherapy resulting in increased DFS and OS at 6 and 10 years of follow up. ${ }^{38,39}$ Patients with stage II disease with negative prognostic factors also benefit from adjuvant chemotherapy. There is however some controversy regarding unselected patients of stage II and also to some extent of stage I, because it is not always objectively possible to make a clear conclusion regarding negative regional lymph node status and the absence of negative pathohistological prognostic factors. ${ }^{40}$

TNM staging has in proportion of patients low prognostic value. Resection of appropriate number of lymph nodes is frequently impossible. In only about $50 \%$ of patients the required resection of 12 lymph nodes is achieved. ${ }^{16,41,42}$ Next to that, light microscopy has its limitations regarding sensitivity regarding detection of malignant cells in regional lymph nodes. ${ }^{43}$ Also only a proportion of a pathological specimen can be examined and this can lead to false negative reports regarding pathological risk factors. ${ }^{17}$ Inadequate resection of appropriate number of lymph nodes and limitations of light microscopy may lead to false downward stage migration. Lymphovascular and perineural invasion are negative prognostic factors, but they can also be underreported. ${ }^{44,45}$ Considering these facts we see, that a substantial proportion of patients is undertreated.

A proportion of patients can have a more malignant phenotype irrespective of the TNM stage and known pathohistological prognostic factors, predisposing them to a more aggressive course of the disease. An intrinsic molecular characteristic, like nucleotide polymorphism, might prove extremely helpful in this regard. Polymorphisms of genes participating in carcinogenesis and disease 
dissemination thereby represent a potential new prognostic marker.

We have investigated patients from northeastern part of Slovenia almost exclusively of Slovenian origin. Our results regarding genotype distribution and connection with pathohistological characteristics are most consistent with study conducted by Dziki et al. ${ }^{29}$ on Polish population, which is as Slovenian also of Slavic origin. Our results compared to other studies are less consistent, but other studies were mainly performed in east Asia and Austria. The differences may be attributable to population genetic differences.

There is however also a question of appropriate study design, especially clinical endpoint. OS is of course the most important endpoint in oncology research, but it may be influenced by many treatment related factors beyond the point of disease relapse. DFS is therefore more appropriate clinical endpoint in resectable disease in research of prognostic markers. Although our results indicate the role of polymorphisms, further research is needed to validate our findings.

Screening of polymorphisms in selected genes of CRC patients in our study suggested that they may have a role as a prognostic factors in resectable CRC. In conclusion, the goal is to identify patients who are going to derive most clinical benefit, without facing unnecessary side effects.

\section{Acknowledgement}

The research was funded by University Medical Centre Maribor as an internal research project IRP2014/01-21.

\section{References}

1. International Agency for Research on Cancer. World cancer report 2014. Stewart B, Wild CP, editors, World Health Organization; 2014.

2. Primic-Žakelj M, Zadnik V, Žagar T, Zakotnik B. Survival of cancer patients, diagnosed in 1991-2005 in Slovenia. Ljubljana: Institute of Oncology Ljubljana, Cancer Registry of Republic of Slovenia; 2009.

3. Cancer incidence in Slovenia 2001. Ljubljana: Institute of Oncology Ljubljana, Cancer Registry of Republic of Slovenia; 2004.

4. Cancer in Slovenia 2010. Ljubljana: Institute of Oncology Ljubljana, Epidemiology and Cancer Registry, Cancer Registry of Republic of Slovenia; 2013.

5. Cancer in Slovenia 2012. Ljubljana: Institute of Oncology Ljubljana, Epidemiology and Cancer Registry, Cancer Registry of Republic of Slovenia; 2015.

6. Allemani C, Weir HK, Carreira H, Harewood R, Spika D, Wang XS, et al. Global surveillance of cancer survival 1995-2009: analysis of individual data for $25,676,887$ patients from 279 population-based registries in 67 countries (CONCORD-2). Lancet 2015; 385: 977-1010.
7. Ries LAG, Melbert D, Krapcho M, Stinchcomb DG, Howlader N, Horner MJ, et al. SEER cancer statistics review, 1975-2005. Bethesda: National Cancer Institute.

8. Weitz J, Koch M, Debus J, Höhler T, Galle PR, Büchler MW. Colorectal cancer. Lancet 2005; 365: 153-65.

9. Kanthan R, Senger JL, Kanthan SC. Molecular events in primary and metastatic colorectal carcinoma: a review. Patholog Res Int 2012; 2012: 597497.

10. lacopetta B. Are there two sides to colorectal cancer? Int J Cancer 2002; 101: 403-8.

11. Benson AB, Schrag D, Somerfield MR, Cohen AM, Figueredo AT, Flynn PJ, et al. American Society of Clinical Oncology recommendations on adjuvant chemotherapy for stage II colon cancer. J Clin Oncol 2004; 22: 3408-19.

12. Engstrom PF, Arnoletti JP, Benson AB, Chen YJ, Choti MA, Cooper HS, et al. NCCN Clinical Practice Guidelines in Oncology: colon cancer. J Natl Compr Canc Netw 2009; 7: 778-831.

13. Labianca R, Nordlinger B, Beretta GD, Brouquet A, Cervantes A, Group EGW. Primary colon cancer: ESMO Clinical Practice Guidelines for diagnosis, adjuvant treatment and follow-up. Ann Oncol 2010; 21(Suppl 5): v70-7.

14. Freeman HJ. Early stage colon cancer. World J Gastroenterol 2013; 19: 846873.

15. Nicastri DG, Doucette JT, Godfrey TE, Hughes SJ. Is occult lymph node disease in colorectal cancer patients clinically significant? A review of the relevant literature. J Mol Diagn 2007; 9: 563-71.

16. Mitchell PJ, Ravi S, Grifftiths B, Reid F, Speake D, Midgley C, et al. Multicentre review of lymph node harvest in colorectal cancer: are we understaging colorectal cancer patients? Int J Colorectal Dis 2009; 24: 915-21.

17. Mejia A, Schulz S, Hyslop T, Weinberg DS, Waldman SA. Molecular staging individualizing cancer management. J Surg Oncol 2012; 105: 468-74.

18. Kang BW, Jeon HS, Chae YS, Lee SJ, Park JY, Choi JE, et al. Association between GWAS-identified genetic variations and disease prognosis for patients with colorectal cancer. PLoS One 2015; 10: e0119649.

19. Kollmar O, Rupertus K, Scheuer C, Junker B, Tilton B, Schilling MK, et al. Stromal cell-derived factor-1 promotes cell migration and tumor growth of colorectal metastasis. Neoplasia 2007; 9: 862-70.

20. Koskensalo S, Louhimo J, Nordling S, Hagström J, Haglund C. MMP-7 as a prognostic marker in colorectal cancer. Tumour Biol 2011; 32: 259-64.

21. Kanzaki $H$, Ouchida $M$, Hanafusa $H$, Sakai $A$, Yamamoto $H$, Suzuki $H$, et al. Single nucleotide polymorphism in the RAD18 gene and risk of colorectal cancer in the Japanese population. Oncol Rep 2007; 18: 1171-5.

22. Stein U, Walther W, Arlt F, Schwabe H, Smith J, Fichtner I, et al. MACC1, a newly identified key regulator of HGF-MET signalling, predicts colon cancer metastasis. Nat Med 2009; 15: 59-67.

23. Ting $L$, Jun $H$, Junjie $C$. RAD18 lives a double life: Its implication in DNA double-strand break repair. DNA Repair (Amst) 2010; 9: 1241-8.

24. Pan J, Chi P, Lu X, Xu Z. Genetic polymorphisms in translesion synthesis genes are associated with colorectal cancer risk and metastasis in Han Chinese. Gene 2012; 504: 151-5.

25. Cañadas I, Taus A, González I, Villanueva X, Gimeno J, Pijuan L, et al. High circulating hepatocyte growth factor levels associate with epithelial to mesenchymal transition and poor outcome in small cell lung cancer patients. Oncotarget 2014; 5: 5246-56.

26. Arlt F, Stein U. Colon cancer metastasis: MACC1 and Met as metastatic pacemakers. Int J Biochem Cell Biol 2009; 41: 2356-9.

27. Lang AH, Geller-Rhomberg S, Winder T, Stark N, Gasser K, Hartmann B, et al. A common variant of the MACC1 gene is significantly associated with overall survival in colorectal cancer patients. BMC Cancer 2012; 12: 20.

28. Muendlein A, Hubalek M, Geller-Rhomberg S, Gasser K, Winder T, Drexel H et al. Significant survival impact of MACC1 polymorphisms in HER2 positive breast cancer patients. Eur J Cancer 2014; 50: 2134-41.

29. Dziki L, Przybyłowska K, Majsterek I, Trzciński R, Mik M, Sygut A. A/G polymorphism of the MMP-7 gene promoter region in colorectal cancer. $\mathrm{Pol}$ Przegl Chir 2011; 83: 622-6.

30. Wieczorek E, Reszka E, Wasowicz W, Grzegorczyk A, Konecki T, Sosnowski M, et al. MMP7 and MMP8 genetic polymorphisms in bladder cancer patients. Cent European J Urol 2014; 66: 405-10. 
31. Peng B, Cao L, Ma X, Wang W, Wang D, Yu L. Meta-analysis of association between matrix metalloproteinases 2, 7 and 9 promoter polymorphisms and cancer risk. Mutagenesis 2010; 25: 371-9.

32. Beeghly-Fadiel A, Shu XO, Long J, Li C, Cai Q, Cai H, et al. Genetic polymorphisms in the MMP-7 gene and breast cancer survival. Int J Cancer 2009; 124: 208-14.

33. Chernov AV, Sounni NE, Remacle AG, Strongin AY. Epigenetic control of the invasion-promoting MT1-MMP/MMP-2/TIMP-2 axis in cancer cells. J Biol Chem 2009; 284: 12727-34.

34. Matsusue R, Kubo H, Hisamori S, Okoshi K, Takagi H, Hida K, et al. Hepatic stellate cells promote liver metastasis of colon cancer cells by the action of SDF-1/CXCR4 axis. Ann Surg Oncol 2009; 16: 2645-53.

35. Coelho A, Calçada C, Catarino R, Pinto D, Fonseca G, Medeiros R. CXCL12-3' A polymorphism and lung cancer metastases protection: new perspectives in immunotherapy? Cancer Immunol Immunother 2006; 55: 639-43.

36. Dommange F, Cartron G, Espanel C, Gallay N, Domenech J, Benboubker L, et al. CXCL12 polymorphism and malignant cell dissemination/tissue infiltration in acute myeloid leukemia. FASEB J 2006; 20: 1913-5.

37. Chang SC, Lin PC, Yang SH, Wang HS, Li AF, Lin JK. SDF-1alpha G801A polymorphism predicts lymph node metastasis in stage T3 colorectal cancer Ann Surg Oncol 2009; 16: 2323-30.

38. Schmoll HJ, Tabernero J, Maroun J, de Braud F, Price T, Van Cutsem E, et al. Capecitabine plus oxaliplatin compared with fluorouracil/folinic acid as adjuvant therapy for stage III colon cancer: final results of the NO16968 randomized controlled phase III trial. J Clin Oncol 2015; 33: 3733-40.

39. André $T$, de Gramont A, Vernerey D, Chibaudel B, Bonnetain F, TijerasRaballand A, et al. Adjuvant fluorouracil, leucovorin, and oxaliplatin in stage II to III colon cancer: updated 10-year survival and outcomes according to BRAF mutation and mismatch repair status of the MOSAIC study. J Clin Oncol 2015; 33: 4176-87

40. Gray R, Barnwell J, McConkey C, Hills RK, Williams NS, Kerr DJ, et al. Adjuvant chemotherapy versus observation in patients with colorectal cancer: a randomised study. Lancet 2007; 370: 2020-9.

41. Inese D, Ilze S, Andrejs V, Janis G. Frequency of morphologic prognostic factors in surgically treated colorectal cancer. Acta Chirurgica Latvensis 2014 14: 3-8.

42. Zhang B, Lv M, Chen T, Wei Q, Wang G, Tian J, et al. The association between lymph node resection and postoperative survival in patients with colorectal cancer. Hepatogastroenterology 2013; 60: 1922-6.

43. Ratto C, Sofo L, Ippoliti M, Merico M, Bossola M, Vecchio FM, et al. Accurate lymph-node detection in colorectal specimens resected for cancer is of prognostic significance. Dis Colon Rectum 1999; 42: 143-54; Discussion 154

44. Liebig C, Ayala G, Wilks J, Verstovsek G, Liu H, Agarwal N, et al. Perineural invasion is an independent predictor of outcome in colorectal cancer. J Clin Oncol 2009; 27: 5131-7.

45. Betge J, Pollheimer MJ, Lindtner RA, Kornprat P, Schlemmer A, Rehak P, et al. Intramural and extramural vascular invasion in colorectal cancer: prognostic significance and quality of pathology reporting. Cancer 2012; 118 $628-38$. 